Article

\title{
The Potential Implications of the Introduction of Bioelectricity in South Korea
}

\author{
Gal Hochman ${ }^{1, *(D)}$ and Chrysostomos Tabakis ${ }^{2}$ \\ 1 Department of Agricultural, Food, \& Resource Economics, Rutgers University, \\ New Brunswick, NJ 08901, USA \\ 2 KDI School of Public Policy and Management, Sejong-si 30149, Korea; ctabakis@kdischool.ac.kr \\ * Correspondence: gal.hochman@rutgers.edu; Tel.: +1-848-932-9142
}

Received: 23 July 2020; Accepted: 10 September 2020; Published: 15 September 2020

\begin{abstract}
We investigate the bioelectricity potential of South Korea and the ramifications of the introduction of biomass use in electricity production for the Korean electricity market. The novelty of our study lies in that we consider a broad portfolio of biomass-energy technologies and carefully analyze their potential economic and environmental implications for South Korea given its biomass availability. To the best of our knowledge, this is the first study to attempt this in the context of South Korea. We first offer a preliminary assessment of South Korea's theoretical biomass potential from forestry residues, livestock manure, and staple crops and of the amount of electricity that could be generated using these different biomass feedstocks. Our analysis suggests that biomass can be used to produce a substantial portion of the total electricity consumed annually in South Korea. In addition, out of all the feedstocks and technologies considered, pyrolysis of forestry residues could potentially impact the electricity market the most. Next, we simulate different bioelectricity supply shocks while randomly perturbing our model's demand and supply elasticity parameters using the Monte Carlo methodology. Our results demonstrate that the introduction of bioelectricity could significantly affect South Korea's electricity market as well as its $\mathrm{CO}_{2}$ emissions.
\end{abstract}

Keywords: bioelectricity; biomass; environmental and economic impact; numerical analysis; partial equilibrium; South Korea

\section{Introduction}

South Korea was the world's ninth-largest energy consumer in 2019 [1]. At the same time, it imports about $98 \%$ of its fossil fuel consumption and ranks among the top five countries globally in terms of imports of liquefied natural gas (LNG), coal, crude oil, and refined products. However, it does not have any international pipeline infrastructure, and thereby imports of LNG and crude oil are exclusively delivered to the Korean market via tankers [2].

South Korea has enjoyed remarkable economic growth and development during the past decades, which has been fueled by rapidly increasing energy use (especially in the industrial and the transportation sectors) [3]. Through much of this period, its energy policies were supply-oriented, mainly aimed at safeguarding a stable energy supply at a low price, and relied on central planning rather than on energy market forces. The high degree of intervention by the Korean government in the energy market contrasts with the U.S. experience in its electricity sector. In particular, since the 1970s, one of the major developments in the electricity sector of the United States has been the development of wholesale and retail competition-along with substantial advances in generation technologies [4].

Looking at electricity generation in South Korea in more detail, coal-fired electricity generation is the most economic form of fossil-based electricity production-as is the case in many other countries-but there are mounting environmental concerns associated with it (note that $40 \%$ of 
the electricity generated in 2016 was coal-based [2]). According to the U.S. Energy Information Administration [5], South Korea's fleet of coal-fired power plants had an average annual capacity factor (i.e., ratio of generation to capacity) of 82\% during the period 2008-2012, with the average for natural-gas-fired and petroleum-fired plants standing at about $40 \%$ over the same period (in comparison, the coal-fired power plants in the United States, Japan, and China recorded over the period 2008-2012 an average annual capacity factor of $66 \%, 62 \%$ and $54 \%$, respectively). These vast differences in the annual capacity factor across plants using different energy sources can be attributed to the significant improvements in the efficiency of coal-fired generation in South Korea-in 2010, $70 \%$ of South Korea's total coal-fired generation came from highly efficient supercritical units-and to the fact that the coal price in South Korea is much lower than the price of imported LNG.

Against this backdrop, the introduction of biomass-based electricity generation can yield substantial benefits to South Korea, especially on the environmental front (note that the terms "biomass-based electricity" and "bioelectricity" are used interchangeably throughout the paper). In fact, it would be in line with the new energy policy paradigm that has emerged in South Korea in recent years mainly as a response to oil market instability, environmental concerns, and concerns about energy supply security [3]. To better address these concerns, South Korea's energy policies have evolved, placing increased emphasis on energy efficiency, renewable energy, privatization of energy-sector activities, and the downscaling of greenhouse gas (GHG) emissions.

Of course, understanding the complex workings of energy systems is of paramount importance for evidence-based energy policymaking. Jebaraj and Iniyan [6] provide a thorough review of the different energy models and discuss the various emerging issues related to energy modeling. They argue that the econometric models reflect the aggregate characteristics of energy supply and consumption and their orientation is towards forecasting (being best suited to short- and medium-term forecasting). They also conclude that the energy-economy models can assist policymaking as they provide insights into the energy-economy interactions. On the other hand, Swan and Ugursal [7] review a subset of these models. In particular, they restrict their attention to models on energy consumption in the residential sector while distinguishing between two approaches: the top-down approach and the bottom-up approach. A major weakness of top-down models is that they provide a very coarse analysis. The bottom-up approach has weaknesses of its own: the bottom-up statistical models often encounter multicollinearity problems, and the bottom-up engineering models are computationally intensive and abstract from economic factors. In more recent papers, Urpelainen and Yang [8] analyze the patterns of variation in power sector reform across 142 developing countries over the period 1982-2013, and Ortner and Totschnig [9] and Kim and Wilson [10] study the energy sector in the European Union with regard to, respectively, the future relevance of electricity balancing markets across Europe and (four) different storylines of future change in its innovation system. Other authors focus on the crude oil and/or natural gas markets. For example, Krichene [11] examines the world markets for crude oil and natural gas over the period 1918-1999. More specifically, Krichene analyzes a time series of crude oil and natural gas output and price data and estimates demand and supply elasticities during two periods: 1918-1973 and 1973-1999. The paper shows that deep changes took place in the market structure following the oil shock in 1973, which can explain the oil and gas price volatility during the period 1973-1999 (in contrast to their relative stability over the period 1918-1973). Finally, in an interesting contribution to energy modeling, Canyurt et al. [12] develop and employ two non-linear forms-exponential and quadratic —of the genetic algorithm energy demand model in order to estimate Turkey's future energy demand based on its gross domestic product (GDP), population, imports, and exports.

Given the large body of literature on energy supply and consumption, what does it say specifically about the energy system in South Korea? As Kim et al. [3] argue, even though nuclear power will continue to play a crucial role in South Korea's energy mix, its aggressive expansion alone will not suffice for South Korea to achieve its "green economy" and GHG emission reduction goals. In fact, the Fukushima episode is likely to make such an expansion politically difficult. Hwang [13] investigates the applicability of the Model for Analysis of Energy Demand (MAED)—created by the International 
Atomic Energy Agency—-to energy demand forecasting by the local governments of South Korea. The MAED is a bottom-up, accounting model, which makes it less demanding than optimization-based or econometric models. Applying this model, Hwang makes projections for the energy demand of Seoul for the period 2015-2035. In addition, Hwang examines the sensitivity of energy demand in Seoul to various policy levers of the Seoul Metropolitan Government, such as the Building Retrofit Program and the plan for electric vehicles. On the other hand, using cointegration methods, Bae [14] estimates the long-run energy demand function for the whole of South Korea and then makes energy demand forecasts up to 2035. Bae finds that there is a cointegration relationship among per capita energy consumption, real GDP per capita, and the energy price index. Additionally, using dynamic ordinary least squares (DOLS), the elasticities with respect to real GDP per capita and the price of energy are estimated to be 1.06 and -0.3 , respectively. Furthermore, demand forecasts based on the DOLS estimation are generally in line with the projections of South Korea's Second National Energy Plan. Lee and Shin [15] focus on electricity demand. They present an electricity demand forecasting model that employs the variable selection and feature extraction methods of data mining to select only relevant input variables and uses the support vector regression method for making accurate predictions. Using subsequently monthly electricity demand data for South Korea over the period 2000-2008, they show that the prediction performance of their model is more promising as compared with that of other frequently used data-mining models. Finally, Shin et al. [16] analyze Korean final energy consumption volatility following an endogenous structural-break approach and demonstrate that it fell by $50 \%$ after January 2002. In terms of energy consumption by sector, they find that the volatility of final energy consumption decreased for the transportation, commercial-household, and public sectors. On the other hand, in terms of energy consumption by source, the consumption volatility of petroleum declined, but the consumption volatility of coal and renewable energy increased. Regarding policy, an important implication that emerges from their results is that the enhancement of energy efficiency and the structural transition from an energy-intensive to an energy-efficient industrial sector should be accelerated so that the stability of Korean energy consumption is preserved.

Other authors look at the Korean natural gas market. For instance, Lee et al. [17] estimate-using ordinary least squares with lagged dependent variable - the city gas demand function for South Korea during the period 1981-2012. Its short-run own-price and income elasticities are estimated to be -0.522 and 0.874 , respectively, implying that the demand for city gas is own-price and income inelastic in the short run. However, their findings reveal that the city gas demand is both own-price and income elastic in the long run. Moreover, Kim et al. [18] estimate the consumption function of natural gas for city gas employing a time-series model with time-varying coefficients. Interestingly, the estimated consumption function is both temperature and GDP elastic.

Last, Chung et al. [19] follow an energy input-output (E-IO) approach to analyze energy consumption in South Korea. In particular, they construct a 96-by-96 hybrid E-IO table-consisting of 14 energy sectors and 82 non-energy sectors of the Korean economy-and use it to estimate the energy intensities and GHG emission intensities associated with energy use for all sectors in the table. In terms of direct energy use, the average values of the direct energy intensity and GHG emission intensity of the 96 economic sectors are 0.186 tons of oil equivalent/million Korean won and $0.315 \mathrm{t}-\mathrm{CO}_{2}$-eq./million Korean won, respectively. On the other hand, in terms of total energy use, the average values of the total (or embodied) energy intensity and GHG emission intensity of these sectors are estimated to be 0.640 tons of oil equivalent/million Korean won and $1.534 \mathrm{t}-\mathrm{CO}_{2}$-eq./million Korean won, respectively. An important lesson that arises for their work is the need to take into account simultaneously the energy intensity and GHG emission intensity of the different sectors in order to design better energy and environmental policies.

In this paper, we investigate the biomass-based electricity potential of South Korea and the implications of the introduction of biomass use in electricity production for the Korean electricity market. The novelty of our study lies in that we consider a broad portfolio of biomass-energy technologies and carefully analyze their potential economic and environmental implications for South 
Korea given its biomass availability (which we actually estimate). To the best of our knowledge, this is the first study to attempt this in the context of South Korea. Our analysis naturally provides important insights for other countries with substantial biomass potential. In fact, the use of biomass for the generation of electricity and/or heat has been studied in the context of many countries-such as Pakistan [20], Portugal [21], and Sweden [22]—as well as from a global perspective [23].

More specifically, we use data from the Korean Statistical Information Service [24] (supplemented with data from the Food and Agriculture Organization of the United Nations [25]) to offer a preliminary assessment of the theoretical (i.e., upper-bound) biomass potential from forestry residues, livestock manure, and staple crops and of the amount of electricity that could be generated using these different biomass feedstocks. Our biomass assessment suggests that biomass can be used to produce a significant portion of the total electricity consumed annually in South Korea, with the most promising feedstock being forestry residues. Notably, out of all the technologies considered, pyrolysis of forestry residues could potentially impact the electricity market the most. Next, we calibrate a linear demand and supply system for the Korean electricity market. To address any uncertainty regarding our model's elasticity parameters, we resort to Monte Carlo simulations. In particular, we simulate different bioelectricity supply shocks while randomly perturbing the demand and supply elasticities (separately). Our analysis illustrates that the introduction of bioelectricity leads to an increase in the total amount of electricity consumed and a decrease in the market price of electricity. As a result, an environmentally detrimental rebound effect arises whereby fossil-based electricity generation declines by less than the size of the biomass-based electricity supply shock simulated. For example, when perturbing the demand elasticity and under an ambitious scenario of a $25 \%$ biomass-based electricity supply shock, fossil-based electricity generation declines by only $10.6 \%$ on average, implying a $57.6 \%$ rebound effect. Still, though, $\mathrm{CO}_{2}$ emissions are mitigated by 94 million tonnes in the most favorable (environmentally) biomass-technology scenario considered. Furthermore, aggregate welfare in the economy does rise.

\section{Materials and Methods}

We now provide a description of the data and methods used in this study. The partial-equilibrium model underlying our analysis is presented in Section 2.1. In Section 2.2, we describe the data and methodology utilized in assessing South Korea's theoretical biomass potential and in estimating the amount of electricity that it could generate using different domestic biomass feedstocks. Last, in Section 2.3, we discuss the methodology followed in order to calibrate the electricity demand and supply functions for South Korea.

\subsection{The Conceptual Model}

When modeling the domestic electricity market of South Korea, we employ a partial-equilibrium framework as it enables us to demonstrate the economic and environmental implications of introducing bioelectricity in a straightforward fashion.

Formally, let $p_{e}$ denote the price of electricity in won per kWh. For simplicity, let us assume that electricity demand, $D\left(p_{e}\right)$, is a linear, downward-sloping function and the supply of electricity from fossil fuels (i.e., coal, natural gas, and crude oil), $S\left(p_{e}\right)$, is a linear, upward-sloping function. Figure 1 depicts the initial equilibrium, which is the point where demand intersects supply (point $A$ in Figure 1) and marginal cost equals price. The initial equilibrium quantity is $q_{e}^{0}$, and the corresponding equilibrium price is $p_{e}^{0}$.

What is the impact of the introduction of bioelectricity on this market? To investigate this, we posit that the utilization of biomass in electricity generation results in a shift of the aggregate electricity supply curve down and to the right (we discuss this assumption in detail in Section 3). More specifically, given the electricity price $p_{e}^{0}$, we maintain the assumption that the introduction of biomass use in electric power production induces the electricity supply curve to shift down and to the right by $B=\frac{X}{100} \cdot q_{e}^{0}$ $\mathrm{kWh}$, where $B$ is the amount of biomass-based electricity (see Figure 2). 


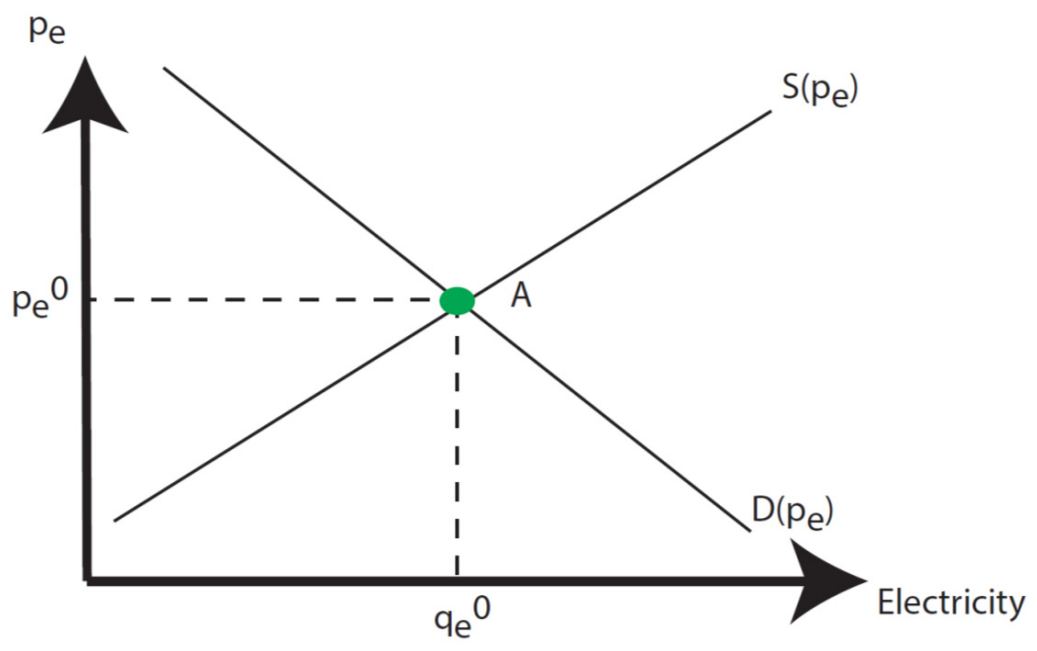

Figure 1. The fossil equilibrium.

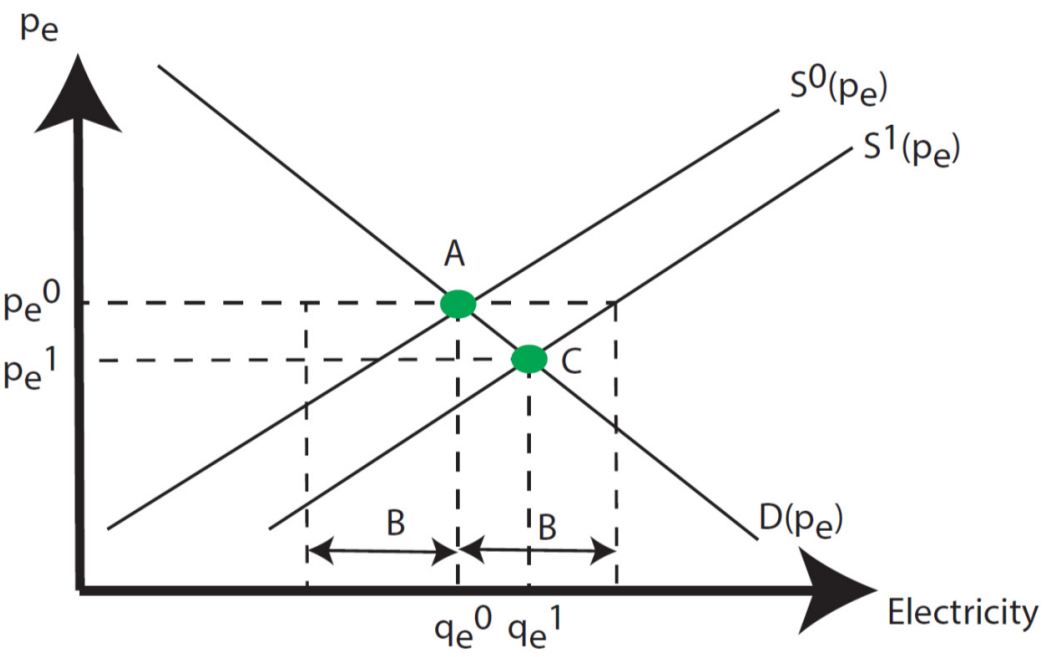

Figure 2. The biomass equilibrium.

\subsection{The Data}

To carry out our analysis, we use data from two different secondary sources: the Korean Statistical Information Service [24] and the Food and Agriculture Organization of the United Nations [25]. The forestry data are taken from the former source (namely, [24]). Although our focus is on the year 2013, data on forestry are collected in 5-year intervals-that is, data for either 2010 or 2015 can be used in our case. When approximating South Korea's theoretical biomass potential, we use the 2015 data. To calculate the potential amount of biomass from forestry residues (in cubic meters), we use the data on forest area and volume and assume a density of $380 \mathrm{~kg}$ per cubic meter solid volume (similar numbers have been used in the literature (e.g., [26]). The reason for the assumption in question is that the data only include information on the types of trees in South Korea and the aggregate area covered by forest and the volume thereof but not on the area covered per tree type. Following Shelly [27], we further assume that 1 bone dry ton produces 1 MWh of electricity.

Next, we look at livestock manure production. The numbers of heads of beef cattle, dairy cows and heifers, pigs, and chickens (layers and broilers) are taken again from the Korean Statistical Information Service [24]. Note here that the data on chickens include information only on broilers and layers-that is, they do not include information on breeding chickens. Furthermore, only chickens in farms that have more than 3000 heads are counted (by complete enumeration). Therefore, the number of chicken 
heads is underestimated in the data. To obtain the amount of volatile solids (VS) that each type of livestock produces, the following equation and values are used:

$$
V S=A P \cdot T A M \cdot v S,
$$

where:

- $A P$ : animal population in number of heads [24]

- $\quad$ TAM: typical animal mass [28]

- $\quad v s:$ average annual production of $V S$ per unit of animal mass [28]

Livestock manure is then converted into million British thermal units (MMBtu) and then into MWh. The VS amount of each type of livestock is converted into MMBtu using the parameters of [28].

The final group of feedstocks considered in our study consists of staple crops: sweet corn and wheat. The data are taken from the Food and Agriculture Organization of the United Nations [25] and are in metric tons (for the year 2013). We convert the values to MMBtu applying the net usable percentage and percent of dry matter parameter values as obtained from [28].

\subsection{Calibration}

In this section, we calibrate the electricity demand and supply functions for South Korea using annual data. Specifically, let us assume the following system of linear demand and supply equations:

$$
\begin{aligned}
& p_{e}=\alpha_{0}-\alpha_{1} \cdot q_{e} \quad \text { (the demand equation) } \\
& p_{e}=\gamma_{0}+\gamma_{1} \cdot q_{e} \quad \text { (the supply equation) }
\end{aligned}
$$

Then, using the definitions of the own-price demand and supply elasticities, we can solve for the slope of the respective equation as follows:

$$
\begin{aligned}
& \alpha_{1}=-\frac{1}{\eta_{d}} \cdot \frac{p_{e}^{0}}{q_{e}^{0}} \\
& \gamma_{1}=\frac{1}{\eta_{s}} \cdot \frac{p_{e}^{0}}{q_{e}^{0}}
\end{aligned}
$$

where $\eta_{d}$ denotes the own-price demand elasticity and $\eta_{s}$ represents the own-price supply elasticity. We then calibrate the intercepts of the two equations using the slopes of the demand and supply curves calculated above:

$$
\begin{aligned}
& \alpha_{0}=p_{e}^{0}+\alpha_{1} \cdot q_{e}^{0} \\
& \gamma_{0}=p_{e}^{0}-\gamma_{1} \cdot q_{e}^{0}
\end{aligned}
$$

The own-price demand elasticity used in the baseline scenario is taken from Table 1 of Cho et al. [29]. Therein, they list estimates-from different countries-of the demand price elasticity for different usage categories as derived in past studies. For the baseline analysis, we use the average elasticity estimate of -0.425 for residential electricity demand in South Korea, originally reported in a study of the Korea Energy Economics Institute [30].

We then perturb the demand elasticity through Monte Carlo simulations to address any uncertainty over this parameter. More specifically, we perform 1000 Monte Carlo trials for each of the different bioelectricity supply shocks we consider (to be discussed below). Each trial is performed by randomizing the demand elasticity and then introducing a predefined shock to the model. For the random sampling, we assume that the own-price demand elasticity of electricity follows a truncated normal distribution with a mean of -0.425 and a standard deviation of 0.1 , with the demand elasticity always being negative.

We could not find information, though, on the supply elasticity of electricity in South Korea; thus, in the baseline scenario, we use the value of 0.3 . Nevertheless, given the uncertainty regarding this parameter, we also perturb the supply elasticity through Monte Carlo simulations in which we assume 
a truncated normal distribution with a mean of 0.3 and a standard deviation of 0.1 (with the supply elasticity being always positive).

When calibrating our system of equations, we use 2013 data on electricity consumption and price as reported by the Korean Statistical Information Service [24]. The quantity (490 TWh) is taken directly from the site, and the price ( 90.48 won per $\mathrm{kWh}$ ) equals the ratio of total electricity sales to end consumers divided by the quantity of electricity consumed.

Finally, using our demand and supply framework, we can calculate consumer surplus and producer surplus as follows:

$$
\begin{gathered}
C S=\int_{p_{e}}^{\alpha_{0}} D(p) d p \\
P S=p_{e} \cdot q_{e}-C\left(q_{e}\right)
\end{gathered}
$$

where $C\left(q_{e}\right)$ denotes the cost of producing $q_{e}$ units of electricity.

\section{Analysis and Results}

The biomass assessment suggests that, theoretically, biomass can be used to generate a significant portion of the total electricity consumed in South Korea (almost 508,000 GWh in 2016 [31]). Although the political-economic potential for biomass-based electricity generation is probably much smaller than the theoretical one [32], it is likely to still be substantial for the Korean electricity market.

Table 1 (see Section 2.2) presents the results of our biomass assessment by summarizing the potential for electricity production from various crops, livestock manure, and forestry residues. As the table clearly illustrates, the most promising feedstock is forestry residues, whereas the staple crop potential is minimal, which is in line with the fact that South Korea imports almost all of the wheat and sweet corn it consumes. Moreover, out of all the technologies considered, pyrolysis of forestry residues could potentially impact the electricity market the most. The theoretical amount of electricity that could be produced via pyrolysis of forestry residues is $1.9 \mathrm{PWh}$. In addition, our analysis shows that the introduction of biomass use in electricity generation results in a decline of the price to end consumers and in an increase in the total amount of electricity consumed-which is in line with the fact that $q_{e}^{0}<q_{e}^{1}$ and $p_{e}^{0}>p_{e}^{1}$ in Figure 2. For example, in the scenario of beef cattle manure utilization and using the baseline parameters, we find that the electricity price could decrease by up to $5.7 \%$; if pig manure were used instead, the price of electricity could fall by $2.3 \%$. (As Table 1 reveals, up to 20,202 GWh of electricity could be produced in the former case; in the latter one, the corresponding figure is $8328 \mathrm{GWh}$.) On the other hand, if forestry residues were utilized in producing electricity, the shock to the market could be of such magnitude that the market price of electricity collapsed.

Overall, the biomass assessment suggests that South Korea can theoretically meet its bioenergy targets without problem, especially by utilizing forestry residues. More specifically, the Renewable Portfolio Standard (RPS) system introduced in 2012 mandates that power producers with installed capacity over 500 MW should produce a minimum portion of their power using renewable energy sources [33]. The yearly RPS target stands at $7 \%$ in 2020 and will rise to $10 \%$ by 2023 . The power producers involved in the RPS system receive certain amount of Renewable Energy Certificates (RECs) annually, certifying that they produced and supplied power using renewable energy sources. (Power generators have the option to meet their obligatory RPS target by purchasing RECs on the market. In case of non-compliance, there is a financial penalty of $150 \%$ of the average REC market price (for the year in question) on every REC missing.) The number of RECs allocated, though, varies depending on the technology used, with the REC weighting scheme placing a relatively high weight on wood biomass as an energy source. Clearly, our biomass assessment demonstrates not only that South Korea can (theoretically) readily meet these renewable energy targets but that there is room for implementing more ambitious ones in the future. 
Table 1. The theoretical (i.e., upper-bound) biomass-based electricity potential of South Korea.

\begin{tabular}{|c|c|c|}
\hline Feedstock & Technology & Quantity (GWh) \\
\hline \multicolumn{3}{|l|}{ Crop } \\
\hline \multicolumn{3}{|l|}{ Wheat } \\
\hline & Direct combustion—stand-alone for solid biomass & 71 \\
\hline & Direct combustion—co-firing & 54 \\
\hline & Gasification-stand-alone for BIGCC & 46 \\
\hline & Pyrolysis & 95 \\
\hline \multicolumn{3}{|l|}{ Sweet Corn } \\
\hline & Direct combustion-stand-alone for solid biomass & 302 \\
\hline & Direct combustion-co-firing & 229 \\
\hline & Gasification-stand-alone for BIGCC & 193 \\
\hline & Pyrolysis & 400 \\
\hline \multicolumn{3}{|l|}{ Livestock } \\
\hline \multicolumn{3}{|l|}{ Beef Cattle } \\
\hline & Direct combustion-ADG/Landfill gas & 12,881 \\
\hline & Direct combustion—stand-alone for solid biomass & 12,928 \\
\hline & Direct combustion—small-scale CHP for solid biomass & 20,202 \\
\hline & Gasification—stand-alone for BIGCC & 8287 \\
\hline & Gasification—small-scale CHP & 15,343 \\
\hline \multicolumn{3}{|c|}{ Dairy Cows and Heifers } \\
\hline & Direct combustion-ADG/Landfill gas & 3466 \\
\hline \multicolumn{3}{|c|}{ 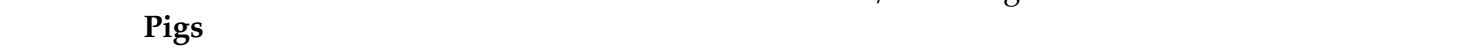 } \\
\hline & Direct combustion-ADG/Landfill gas & 8328 \\
\hline \multicolumn{3}{|l|}{ Chickens } \\
\hline & Direct combustion-ADG/Landfill gas & 3808 \\
\hline & Direct combustion-stand-alone for solid biomass & 3822 \\
\hline & Direct combustion—small-scale CHP for solid biomass & 5973 \\
\hline & Gasification—stand-alone for BIGCC & 2450 \\
\hline & Gasification—small-scale CHP & 4536 \\
\hline \multicolumn{3}{|c|}{ Forestry Residues } \\
\hline & Direct combustion-stand-alone for solid biomass & $1,405,858$ \\
\hline & Direct combustion-co-firing & $1,068,040$ \\
\hline & Gasification-stand-alone for BIGCC & 901,191 \\
\hline & Pyrolysis & $1,864,178$ \\
\hline
\end{tabular}

Before proceeding further, a few remarks are in order. When assessing the net benefits from the expansion of bioenergy, the direct (and indirect) costs associated with the use of biomass in electricity generation should be carefully accounted for. However, some of the technologies listed in Table 1 are only at the research and development stage and have not been commercialized yet. Others that have been commercialized are currently employed to some extent only and gradually becoming cost-competitive (e.g., biomass anaerobic digestion or biomass combined heat and power). Nevertheless, as past experience has shown, learning by doing and learning by researching can be very substantial in the renewable energy industry $[34,35]$, which suggests that renewable technologies should be evaluated from a dynamic point of view. For instance, there was a sharp drop in solar and wind energy costs (more precisely, in cost per kWh) in the United States within the timespan of a few decades. Furthermore, focusing on biomass, co-firing (i.e., the simultaneous combustion of different fuels in the same boiler) wood biomass with coal in existing coal plants has much potential relative to other renewable technologies assuming that the wood biomass feedstock is sufficiently clean relative to coal (e.g., it is not the product of logging of natural forest). The U.S. Energy Information Administration [36] derived and compared updated cost estimates for different generic utility-scale electricity generating technologies. These updated estimates reveal that, for a pulverized coal plant retrofitted to operate with 10\% wood biomass fuel and with capacity of $300 \mathrm{MW}$ (and heat rate of 
$10,360 \mathrm{Btu} / \mathrm{kWh}$ ), its overnight capital cost, fixed non-fuel operations and maintenance (O\&M) costs, and variable O\&M costs equal USD 537/kW, USD 50.9/kW-yr, and USD 5/MWh, respectively. On the other hand, for an onshore wind facility of $100 \mathrm{MW}$ and a photovoltaic tracker facility of $150 \mathrm{MW}$, the overnight capital cost equals, respectively, USD 1877/kW and USD 2534/kW; these facilities though are characterized by lower fixed O\&M costs (of USD 39.7/kW-yr and USD 21.8/kW-yr, respectively) and by zero variable O\&M costs.

A final remark relates to the cost of air pollution (e.g., health costs due to air pollution). The generation of electricity from fossil fuels results in significant GHG emissions, imposing a cost on society both locally and globally. Furthermore, Pareto efficiency dictates that, in policy design, we should not restrict our attention solely to the private cost of electricity production (i.e., the cost borne by the electricity producers). Rather, the (marginal) external cost that electricity production imposes on society via pollution should also be explicitly taken into account. Therefore, when the social cost of electricity production is considered-which equals the sum of the private cost and the external cost of production - the cost competitiveness of renewable electricity generation vis-à-vis fossil-fired electricity generation improves significantly [37] and (some) low-carbon electricity technologies can become competitive with the fossil ones (which is consistent with the downward shift of the supply curve in Figure 2). (A negative production externality, such as air pollution, can be efficiently addressed by a Pigouvian tax. In our case, an optimal carbon tax could render low-carbon electricity technologies cost-competitive even on a private-cost basis.)

Due to the many unknown parameters, which depend as we just discussed, among others, on the research and development of biomass-energy technologies and their commercialization and adoption, we simulate various supply-shock scenarios arising from the introduction of biomass use in electricity production. To this end, we employ the Monte Carlo methodology described in Section 2.3 and analyze different supply-shock scenarios perturbing first the demand elasticity. In Figure 3, we depict the distribution of the changes in the total quantity of electricity consumed arising from 1000 Monte Carlo simulations for two alternative bioelectricity supply shocks: $5 \%$ and $25 \%$ of the total electricity consumed in South Korea in the year 2013. (We present in detail the simulation results for these two shocks as they can be reasonably viewed as a "modest" and an "ambitious" biomass-energy scenario for South Korea. We additionally discuss the results emerging from a "medium" supply shock at the end of this section. The simulation results for other supply shocks are available from the authors upon request.) The distribution of the price changes for these two shocks is depicted in Figure 4. In the case of the $5 \%$ shock, the total amount of electricity consumed increases by $2.9 \%$ (see Figure 3), while the market price of electricity decreases by $7.1 \%$ (see Figure 4). Similar effects in terms of sign (but, as expected, of larger magnitude) are documented when applying the $25 \%$ shock. The main difference-which arises from the assumption of a linear demand function and because the amount of biomass-based electricity introduced in the second scenario (namely, the $25 \%$-shock scenario) is substantially larger-is that the distributions of quantity and price changes in the $25 \%$-shock scenario are more dispersed.

Since a bioelectricity supply shock results in the electricity price decreasing, an environmentally detrimental rebound effect arises as fossil-based electricity generation declines by less than the size of the bioelectricity shock in question (see Figure 5; in terms of Figure 2, point $C$ (the new equilibrium) is down and to the right of point $A$ (the initial equilibrium), and the new amount of fossil-based electricity consumed is $q_{e}^{1}-B>q_{e}^{0}-B$ - the rebound effect, then, is equal to $\frac{q_{e}^{1}-q_{e}^{0}}{B}$ ). In Figure 6, we depict this rebound effect. In particular, in the $5 \%$-shock scenario, there is a decline of only $2.1 \%$ on average in the total amount of electricity produced from non-biomass sources. In other words, the $5 \%$ shock results in a $57.6 \%$ rebound effect. Similarly, under the (more) ambitious $25 \%$-shock scenario, fossil-based electricity generation decreases by $10.6 \%$ on average. 


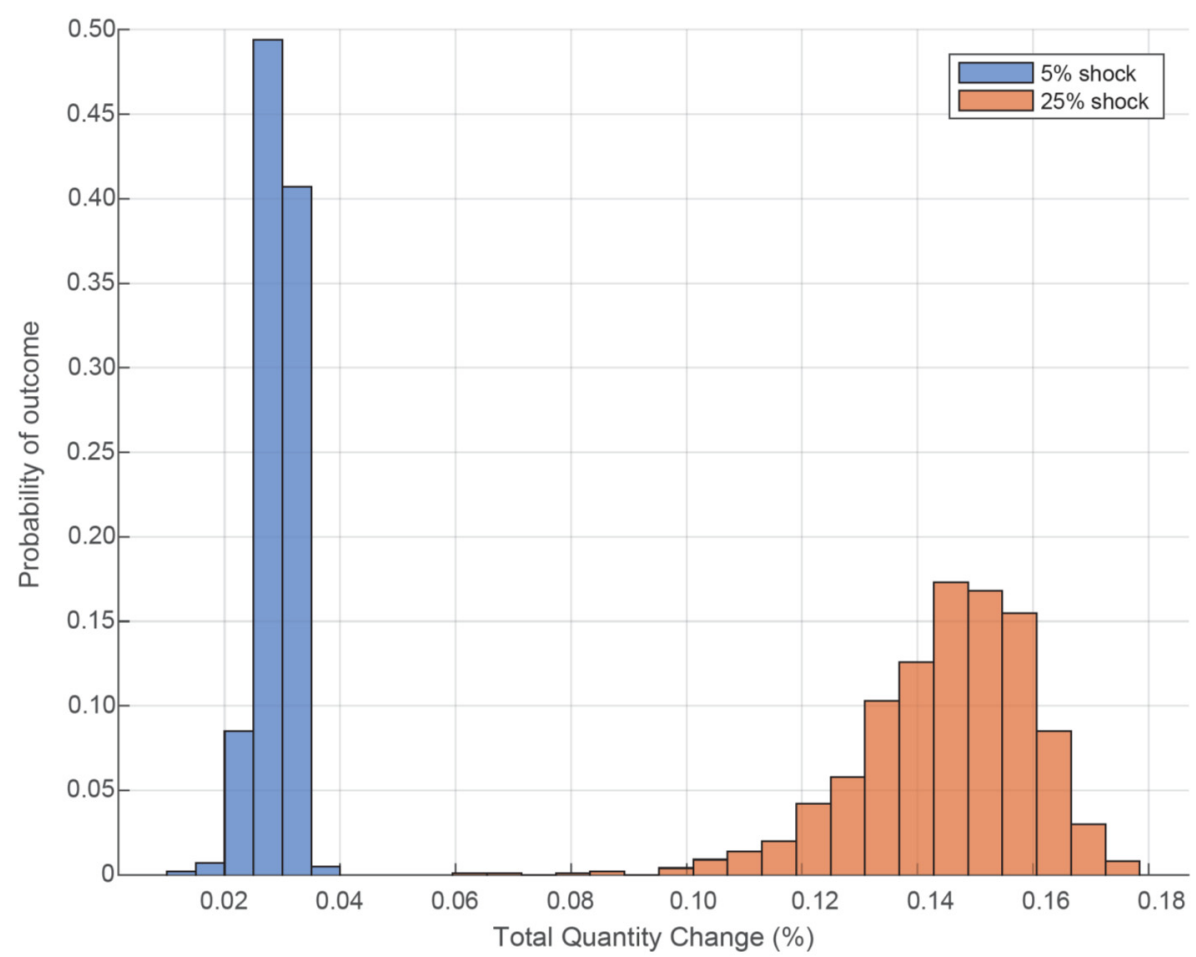

Figure 3. Change in electricity consumption after supply shock (demand simulations).

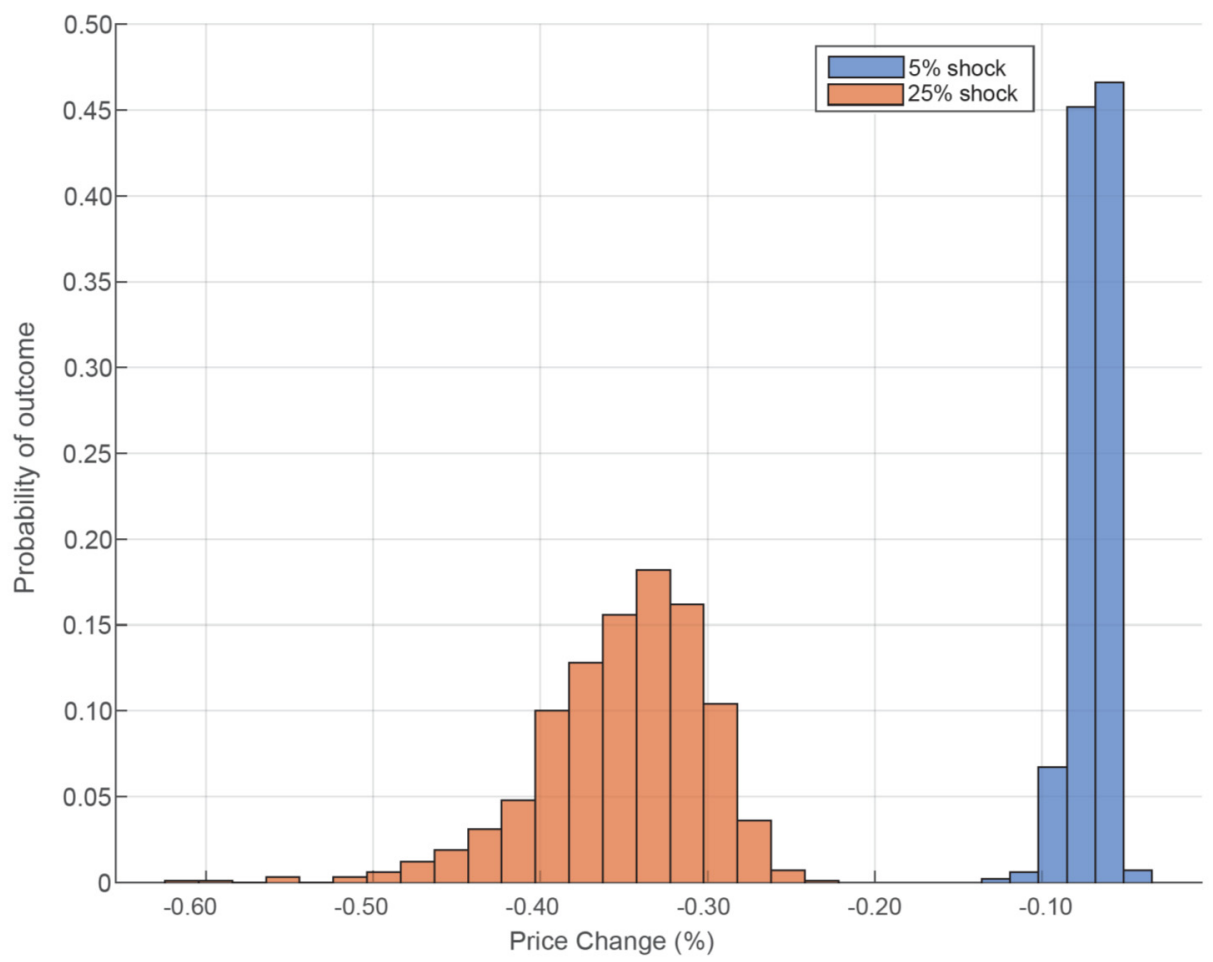

Figure 4. Change in electricity price after supply shock (demand simulations). 


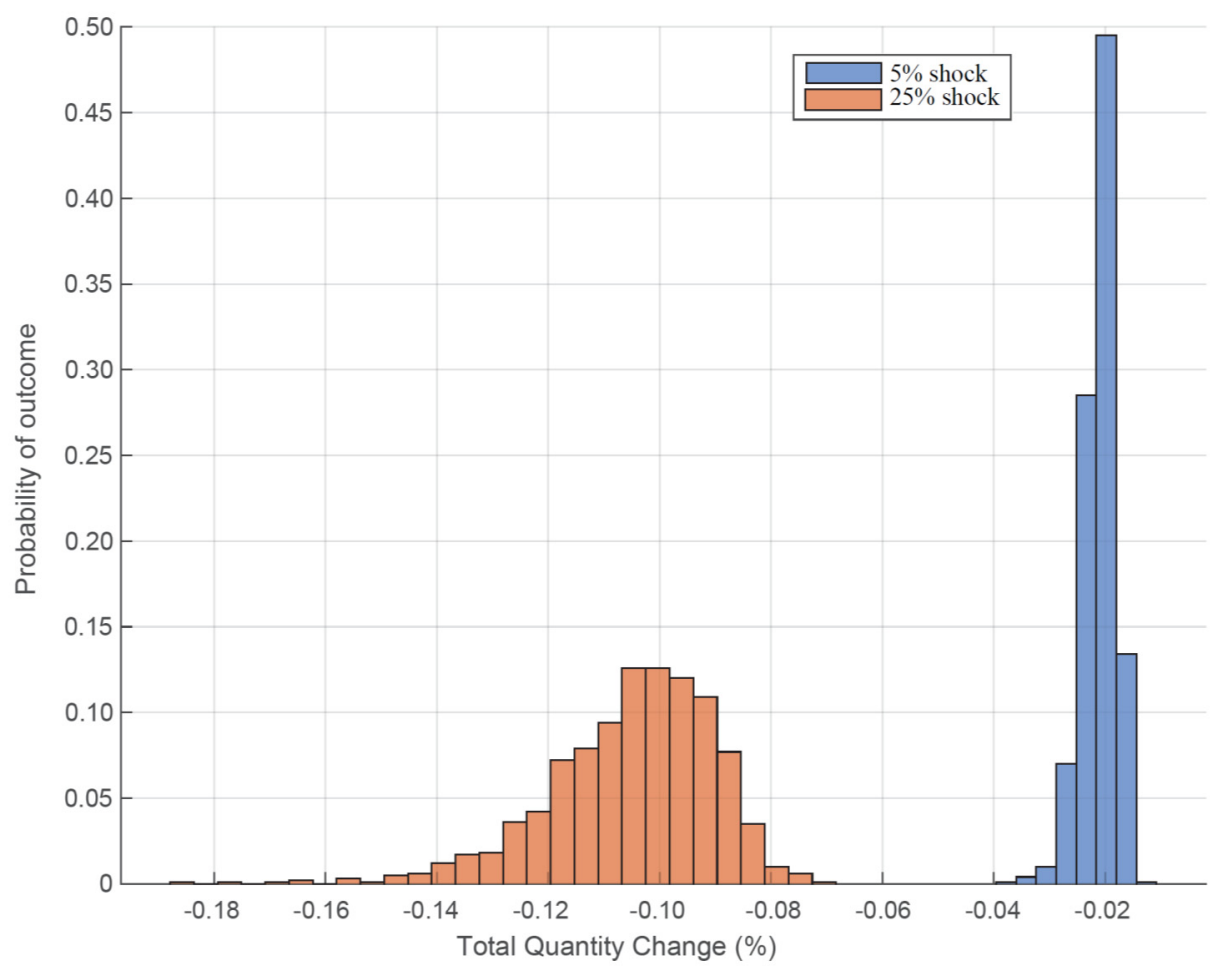

Figure 5. Change in fossil-based electricity consumption after supply shock (demand simulations).

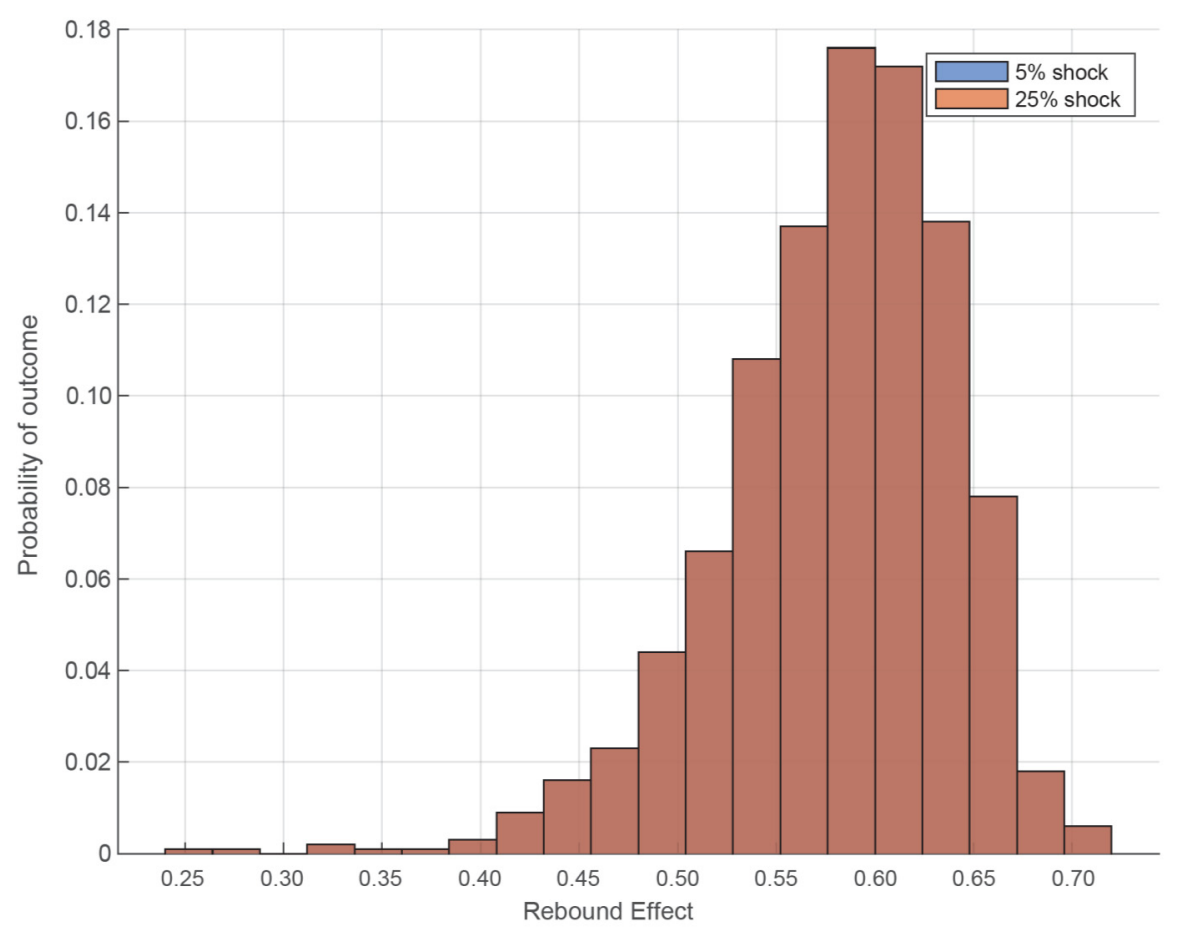

Figure 6. Rebound effect after supply shock (demand simulations).

The rebound effect does mitigate the environmental benefits from the utilization of biomass in electricity generation. To examine the ramifications of biomass-energy introduction for $\mathrm{CO}_{2}$ emissions, we build upon Spath and Mann [38] while using estimates from the U.S. Energy Information Administration [39] and investigate three alternative biomass-technology scenarios: (i) a coal system with biomass co-firing and 15\% co-firing rate (scenario 1); (ii) a biomass residue direct-fired system (scenario 2); (iii) a biomass dedicated feedstock integrated gasification combined cycle (IGCC) system 
(scenario 3). For all three scenarios analyzed, the baseline scenario is a pulverized-coal-fired system; in addition, in the first two scenarios, the biomass is assumed to be produced by urban sources and diverted from normal landfilling and mulching operations. For the $5 \%$ shock, $\mathrm{CO}_{2}$ emissions decline by 18.8 million tonnes in scenario 2 (see Figure $7 \mathrm{c}$ ) and by 7.6 million tonnes in scenario 3 (see Figure $7 \mathrm{~b}$ ) but increase by 8 million tonnes in scenario 1 (see Figure 7a). The increase in $\mathrm{CO}_{2}$ emissions in the last case is due to the rebound effect and the fact that, on a life-cycle basis, $\mathrm{CO}_{2}$ emissions per $\mathrm{kWh}$ of electricity produced only moderately decrease in scenario 1 in comparison with the baseline scenario. Moreover, in the case of the $25 \%$ biomass-based electricity supply shock, $\mathrm{CO}_{2}$ emissions are reduced by 94 million tonnes in scenario 2 and by 38.1 million tonnes in scenario 3 but are higher by 39.9 million tonnes in scenario 1.

Next, to further address any uncertainty regarding the parameters used to calibrate the model, we also perturb the supply elasticity, sampling 1000 times from a truncated normal distribution with a mean of 0.3 and a standard deviation of 0.1 . The results of these simulations are presented in Figures 8-10. As with the demand-elasticity Monte Carlo simulations, the 5\% shock results in the electricity price dropping and total electricity production increasing by $7.1 \%$ and $3 \%$, respectively, while the $25 \%$ shock has (as expected) more pronounced effects on the electricity market. The amount of fossil-based electricity generation declines by $2 \%$ in the $5 \%$-shock scenario and by $9.8 \%$ in the $25 \%$-shock one. The rebound effect is thereby somewhat larger than that reported when randomly perturbing the demand elasticity and equals (in both scenarios) $60.6 \%$ (see Figure 10). Again, the effect on $\mathrm{CO}_{2}$ emissions depends on the biomass-technology scenario considered. For the $5 \%$ shock, $\mathrm{CO}_{2}$ emissions decrease by 18.4 million tonnes in scenario 2 (namely, a biomass residue direct-fired system; see Figure 9c) and by 7 million tonnes in scenario 3 (namely, a biomass dedicated feedstock IGCC system; see Figure 9b) but increase by 8.4 million tonnes in scenario 1 (namely, a coal system with biomass co-firing; see Figure 9 a). The corresponding figures for the $25 \%$ biomass-based electricity supply shock are 92.2, 34.9, and 42 million tonnes, respectively.

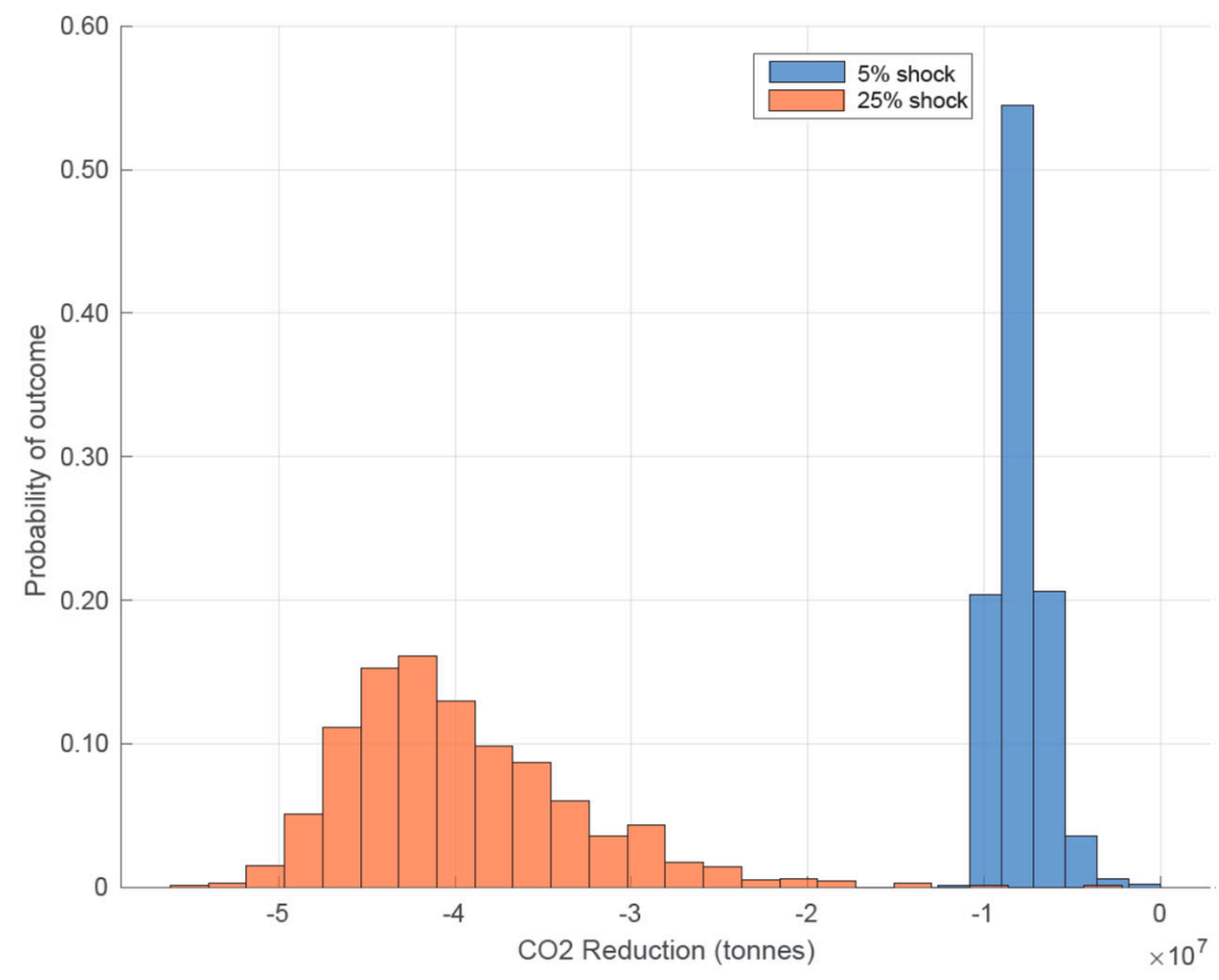

(a) A coal system with biomass co-firing and $15 \%$ co-firing rate (scenario 1).

Figure 7. Cont. 


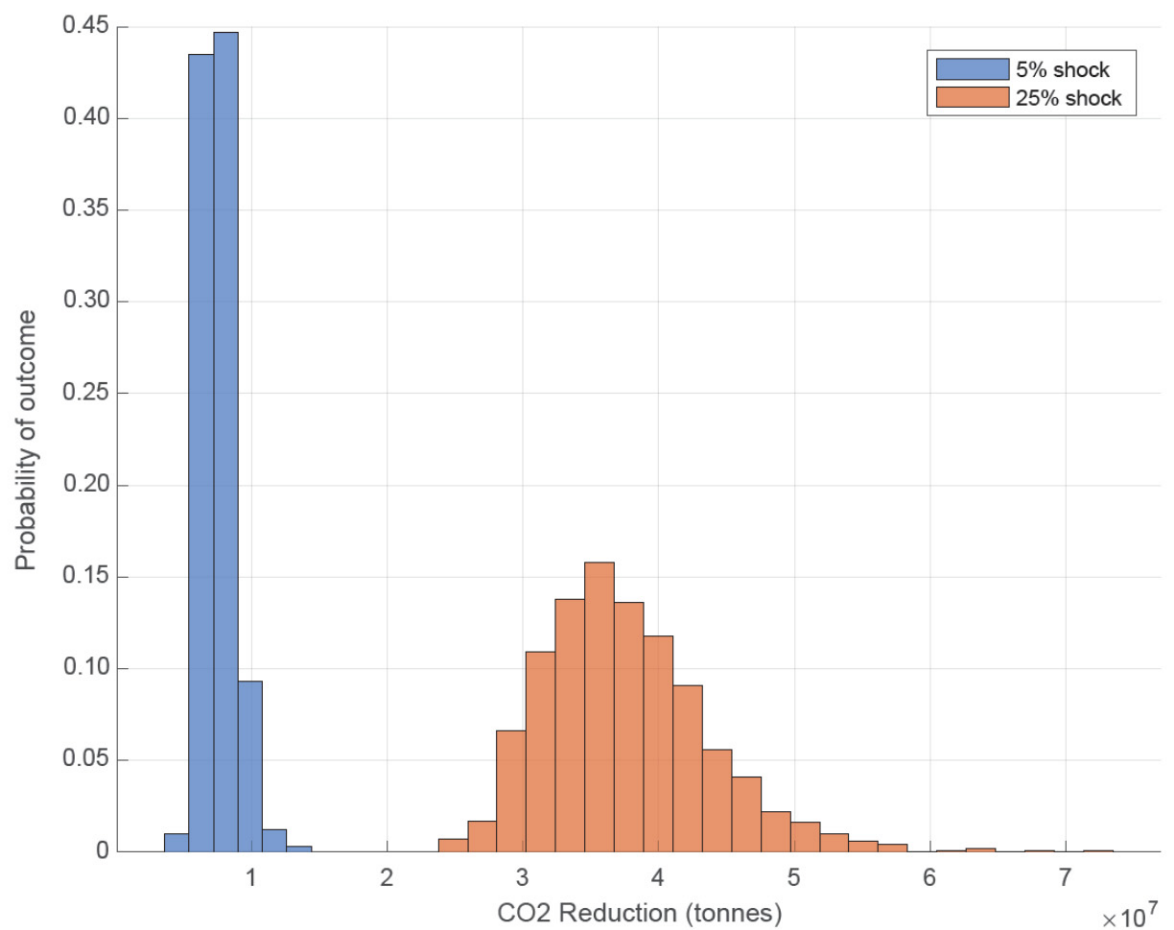

(b) A biomass dedicated feedstock integrated gasification combined cycle (IGCC) system (scenario 3).

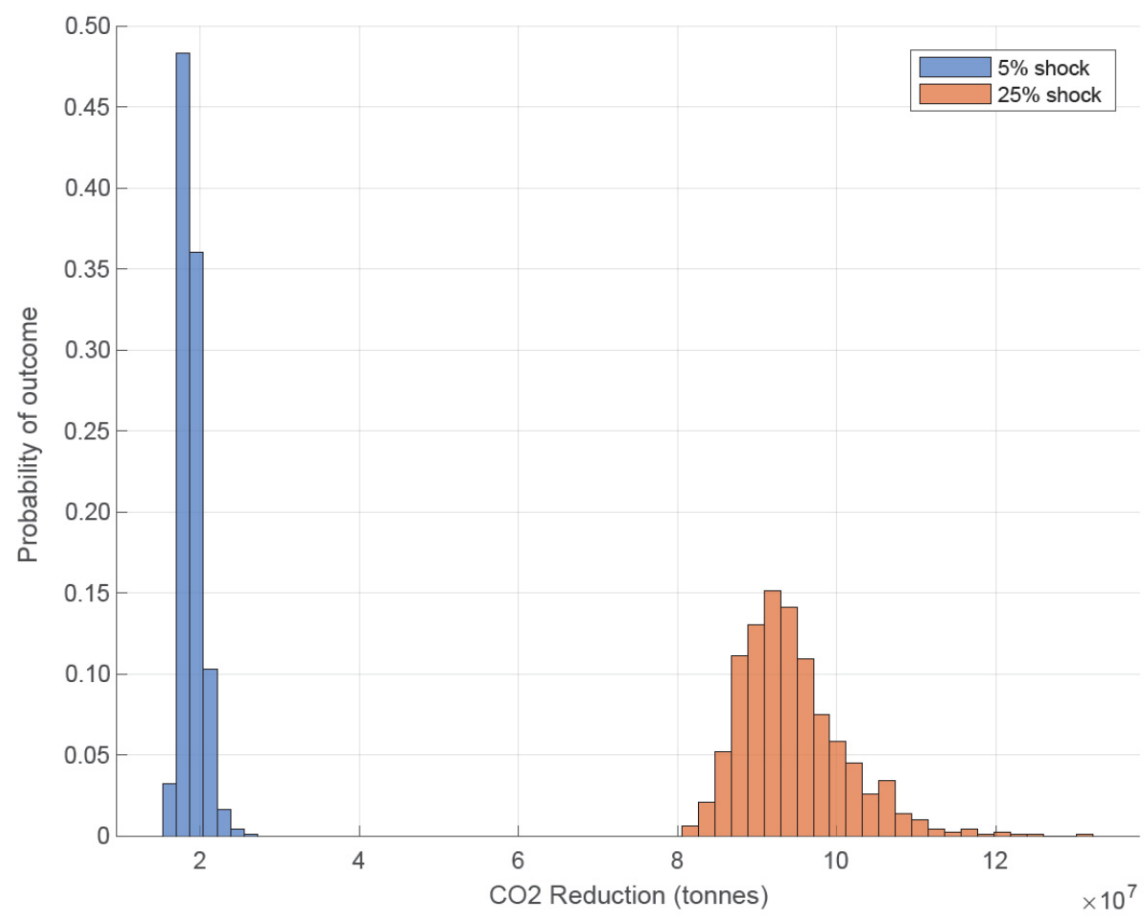

(c) A biomass residue direct-fired system (scenario 2).

Figure 7. Change in $\mathrm{CO}_{2}$ emissions after supply shock (demand simulations). 


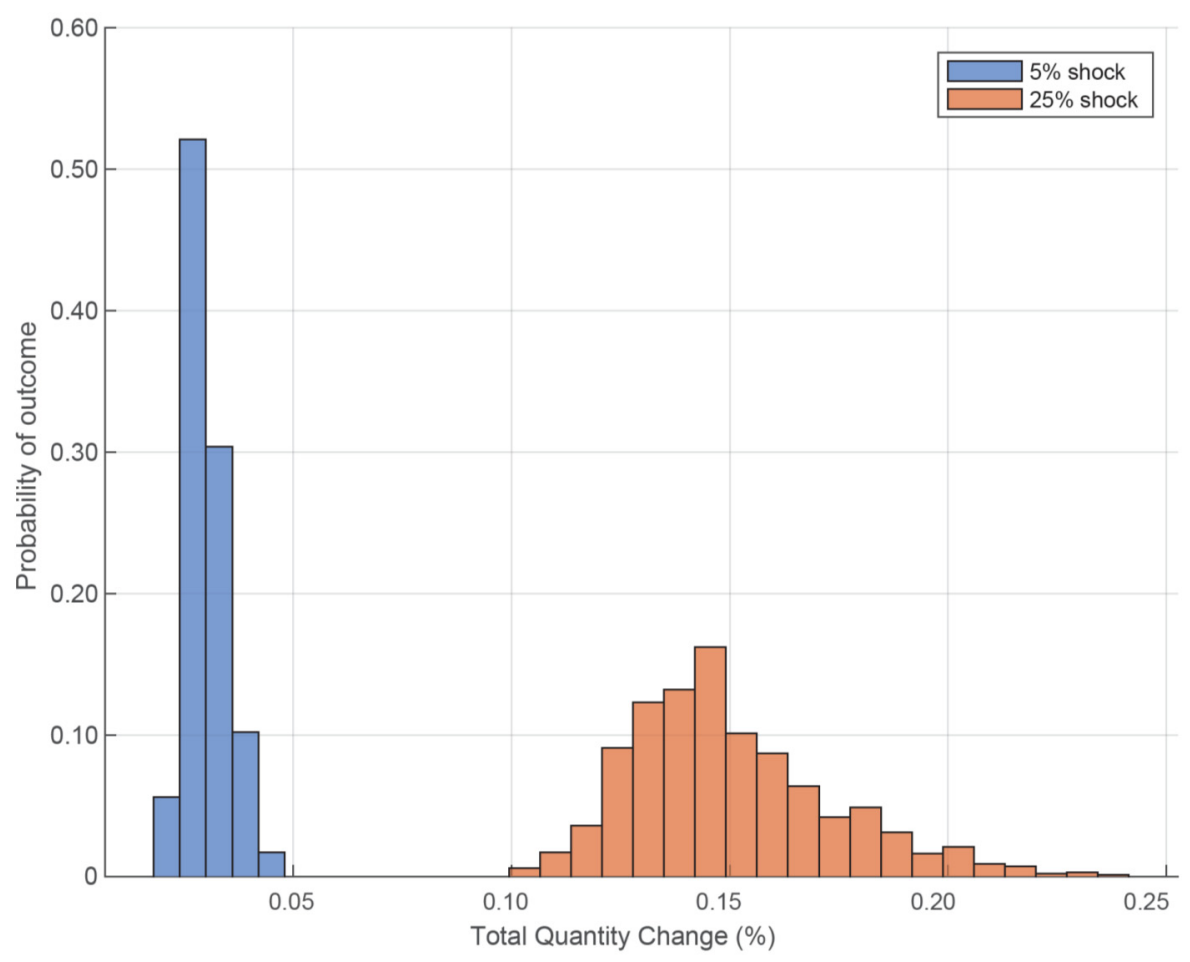

Figure 8. Change in electricity consumption after supply shock (supply simulations).

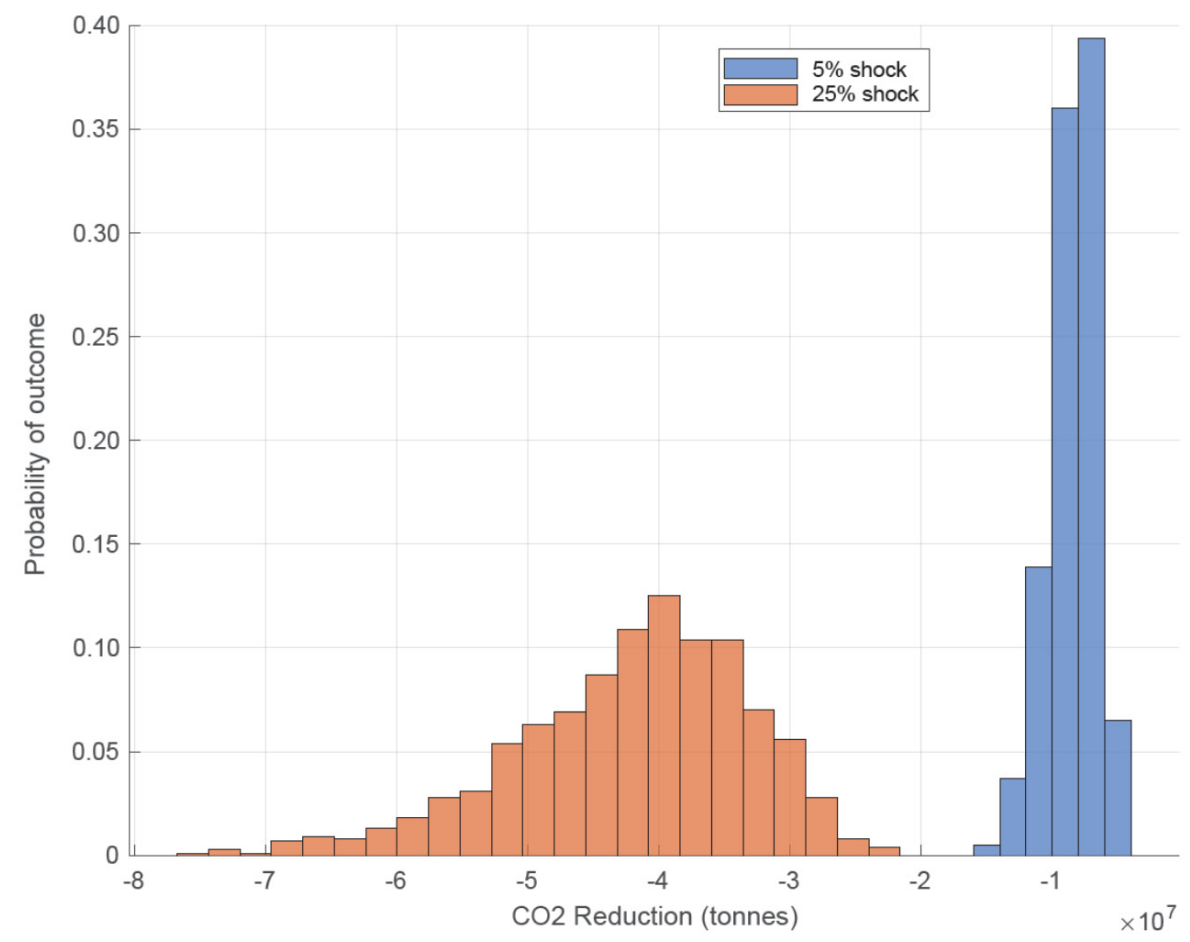

(a) A coal system with biomass co-firing and $15 \%$ co-firing rate (scenario 1).

Figure 9. Cont. 


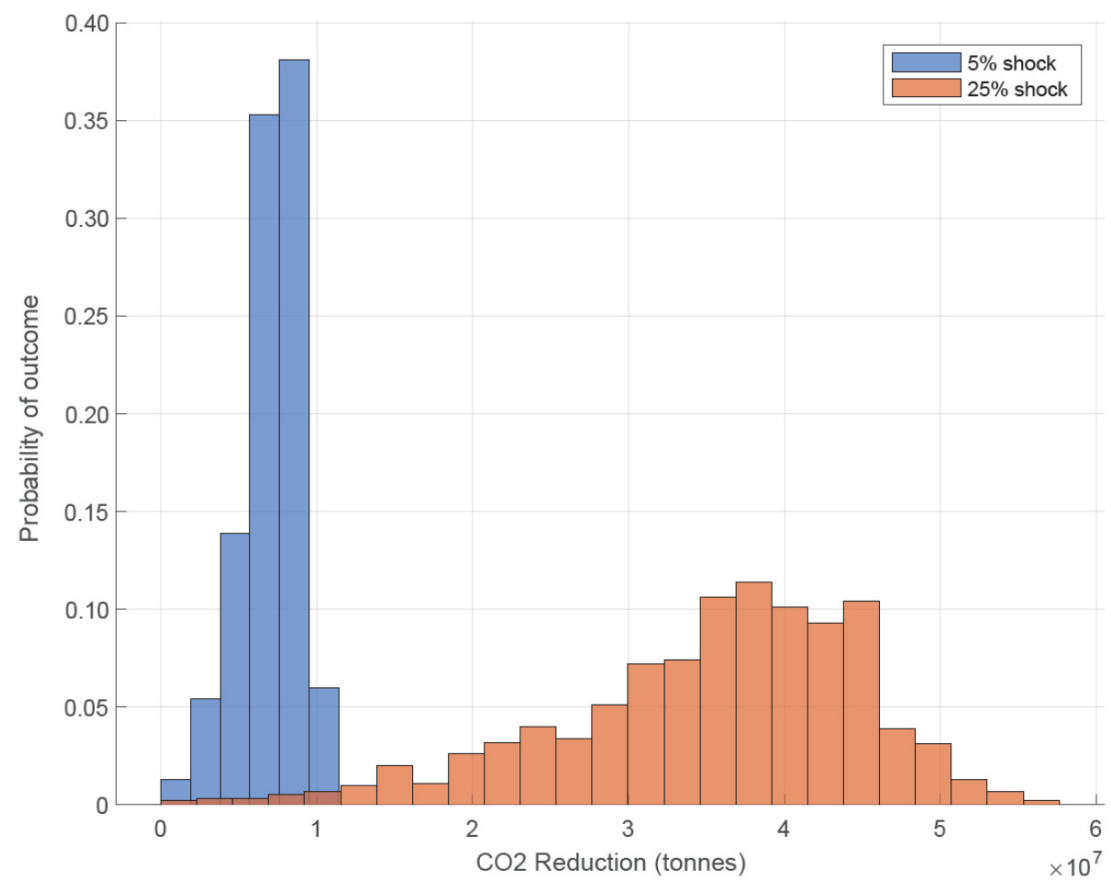

(b) A biomass dedicated feedstock integrated gasification combined cycle (IGCC) system (scenario 3).

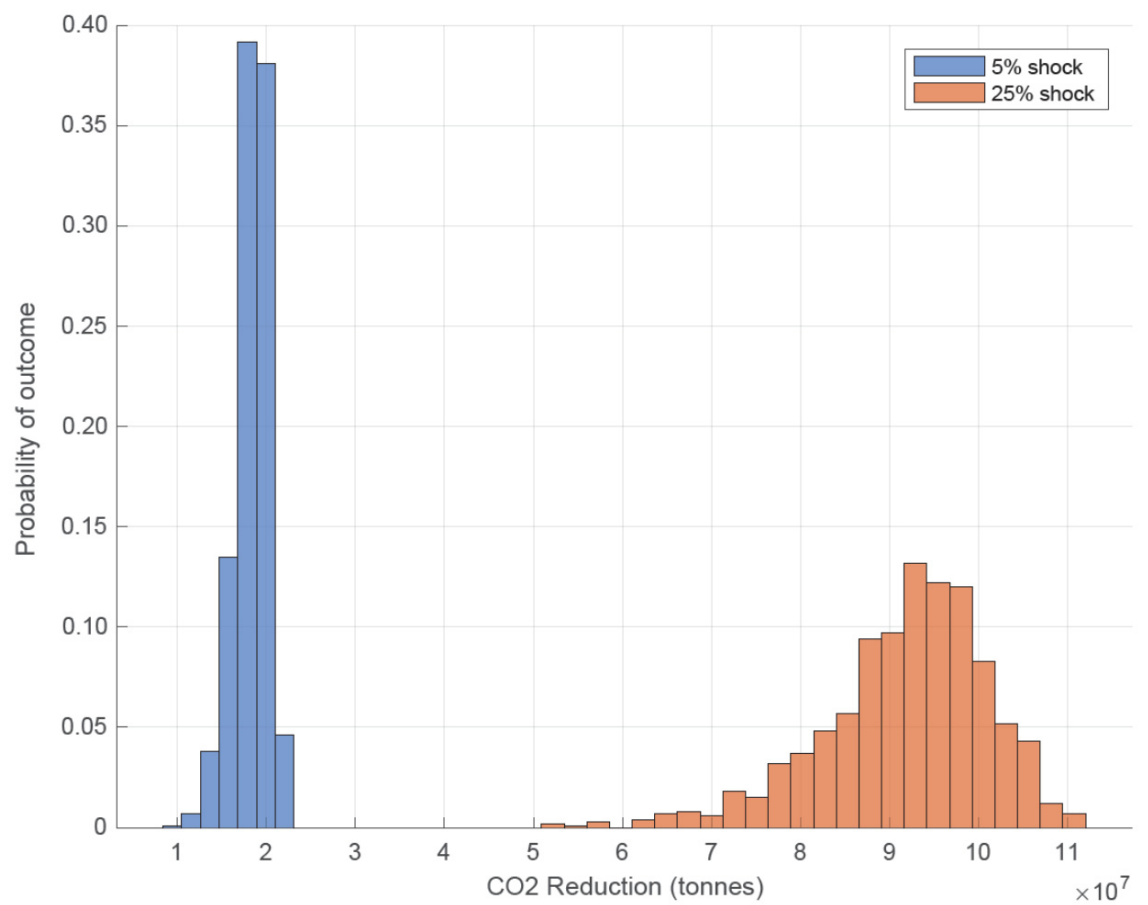

(c) A biomass residue direct-fired system (scenario 2).

Figure 9. Change in $\mathrm{CO}_{2}$ emissions after supply shock (supply simulations). 


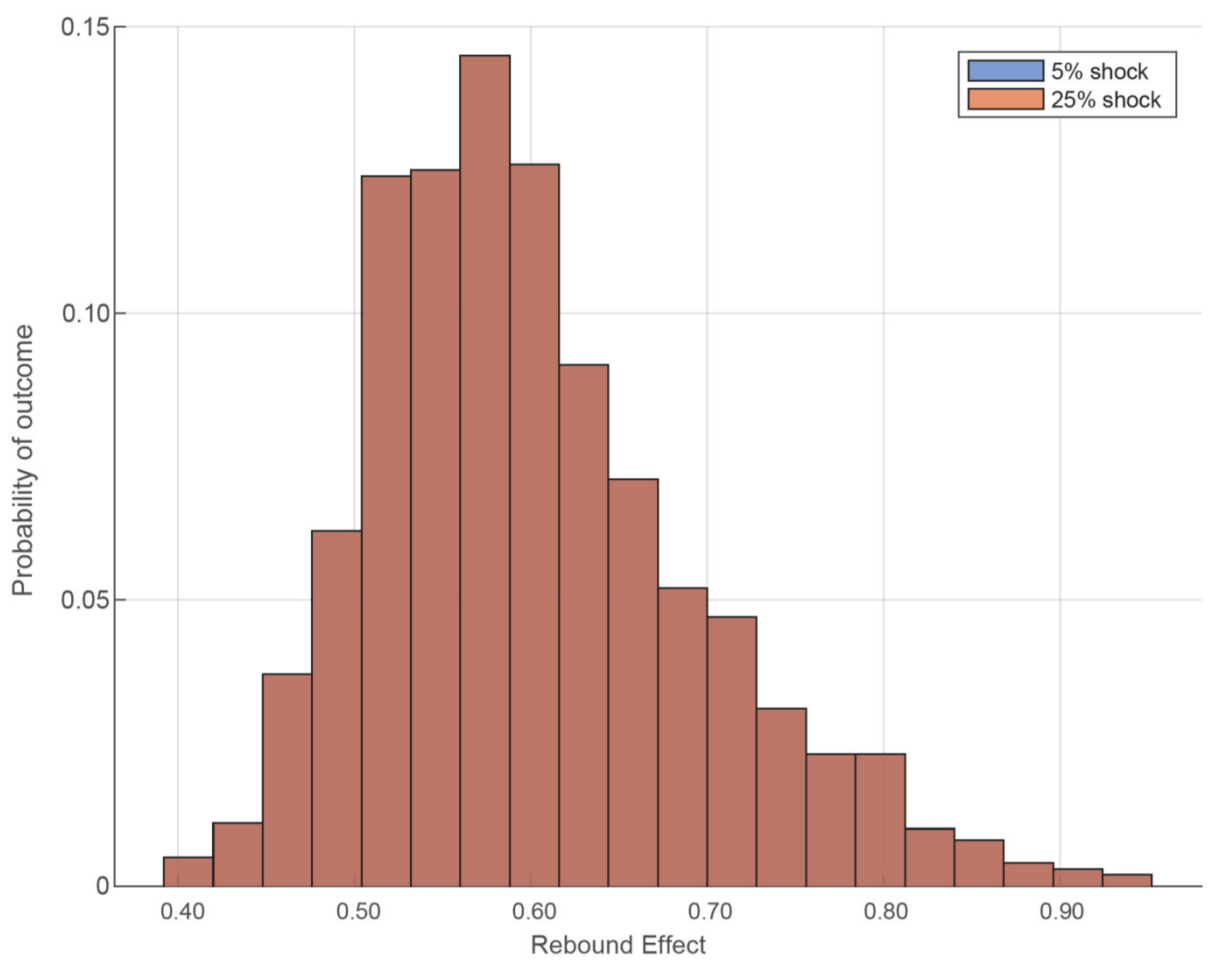

Figure 10. Rebound effect after supply shock (supply simulations).

In order to provide some further insights into the potential impact of biomass-based electricity on the Korean electricity market, we now discuss the results emerging from a 15\% supply shock, which can be viewed as a "medium" bioelectricity scenario for South Korea. Starting with the demand-elasticity simulations, we find that, on average: (i) electricity consumption rises by $8.6 \%$; (ii) the price of electricity drops by $21.2 \%$; (iii) fossil-based electricity generation decreases by $6.4 \%$; (iv) $\mathrm{CO}_{2}$ emissions are mitigated by 56.4 and 22.8 million tonnes in biomass-technology scenarios 2 and 3, respectively, but are higher by 23.9 million tonnes in the case of a coal system with biomass co-firing. Similarly, when perturbing the supply elasticity, the following results arise: (i) total electricity production increases by $9.1 \%$; (ii) the market price of electricity falls by $21.4 \%$; (iii) electricity generation from fossil sources decreases by $5.9 \%$; (iv) $\mathrm{CO}_{2}$ emissions are reduced by 55.3 and 20.9 million tonnes in biomass-technology scenarios 2 and 3, respectively, but are higher by 25.2 million tonnes in scenario 1 . In brief, our findings demonstrate that even a medium bioelectricity supply shock of $15 \%$ could have very significant economic and environmental implications for South Korea.

Finally, we look at the ramifications of different bioelectricity supply shocks for consumer surplus, the surplus of fossil-based electricity producers, and the total revenue from biomass-based electricity production (using the baseline parameters). The changes in the surpluses/revenue over different such supply shocks are depicted in Figure 11, where the sum of the three changes (i.e., welfare change) is positive and increasing over the range of the shocks considered. Clearly, the total gain for the Korean economy is lower than the welfare gain reported in Figure 11 because the cost of producing biomass-based electricity needs to be taken into account. Nevertheless, we do not have reliable cost estimates to use for calculating the surplus of bioelectricity producers as, for instance, some of the technologies included in our analysis are-as we already discussed above-at the research and development stage and have not been commercialized yet. Having said that, the effect on consumer surplus is large and more than likely to compensate for the bioelectricity production costs. 


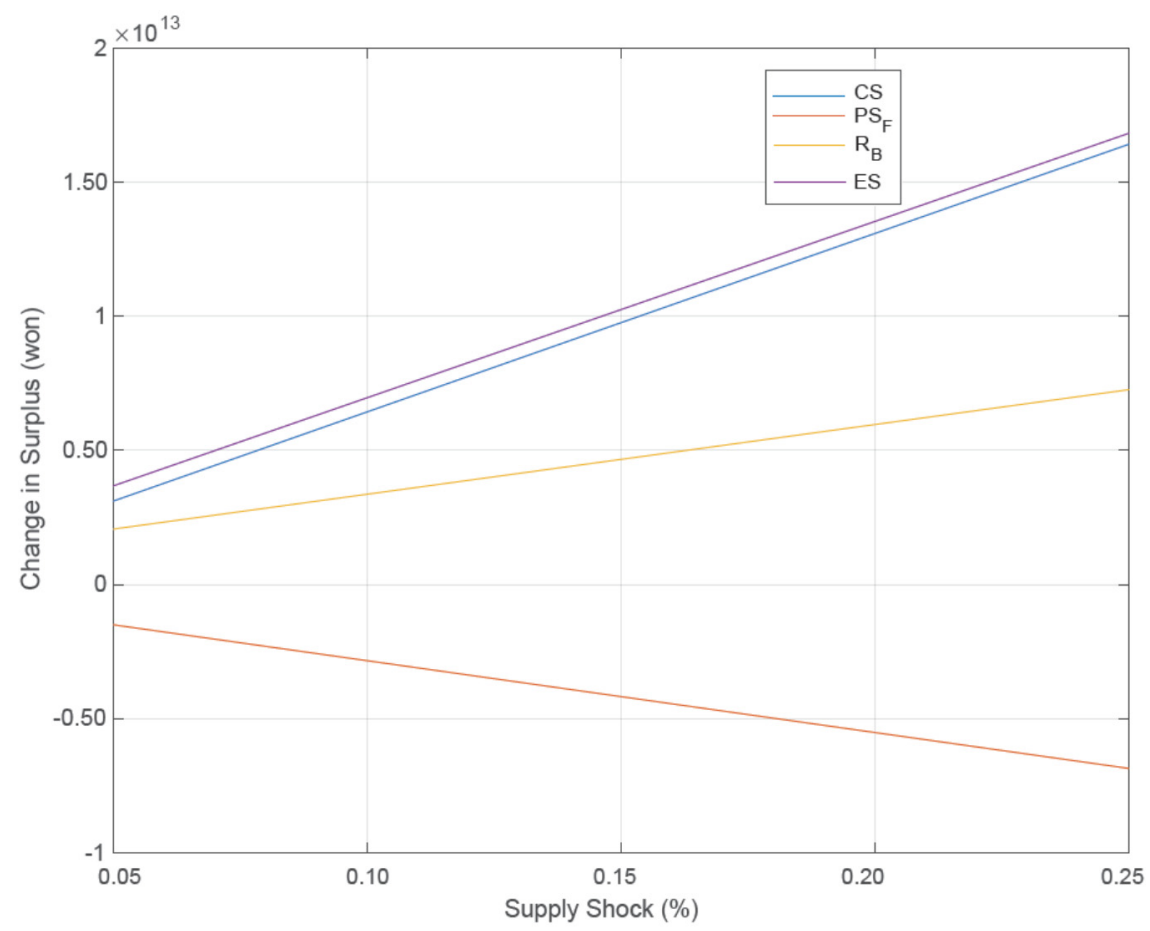

Figure 11. Welfare change (baseline parameters).

\section{Discussion and Policy Implications}

Future work, we believe, should offer a more comprehensive assessment of South Korea's biomass-based electricity potential along several dimensions. In particular, the analysis should take into account the spatial distribution of the domestic biomass resources-which is not feasible, to the best of our knowledge, with the data currently available - thus identifying regional low-carbon energy pathways and potential supply chain structures that are or could become economically viable (in the future). Moreover, the analysis should explicitly consider political-economic and logistical constraints, such as policy and institutional barriers, political constraints, and infrastructure constraints. Such a comprehensive assessment will more accurately evaluate the economic viability and the environmental ramifications of biomass-based electricity generation in South Korea. Still, our analysis constitutes an important first step in this direction.

It is important to further note that, in practice, the introduction of biomass-based electricity generation depends both on the successful research and development of biomass-energy technologies and, afterwards, on their successful commercialization and adoption. It is true that some of the technologies considered in our analysis are only at the research and development stage and have not been commercialized yet and that others that have been commercialized are currently employed to some extent only and are gradually becoming cost-competitive. Nevertheless, if past experience is any guide, learning by doing and learning by researching can be very substantial in the renewable energy industry, suggesting that renewable technologies should be evaluated from a dynamic point of view. In addition, from a Pareto efficiency perspective, the external cost that electricity production imposes on society via pollution should be explicitly taken into account in policy design. If so, the competitiveness-in terms of social cost of production —of renewable electricity generation vis-à-vis fossil-fired electricity generation improves significantly and (some) clean technologies can become competitive with the fossil ones. This might be even more the case for South Korea, where the fossil feedstocks are delivered to the domestic market via expensive means, such as tanker or bulk carrier shipments. However, before moving to large-scale deployment of bioelectricity, its land-use implications should be better understood. This is an important issue, but we leave it for future research. 
Furthermore, one important lesson that emerges from our analysis is that the rebound effect has important implications for the impact of biomass-energy introduction on $\mathrm{CO}_{2}$ emissions (assuming that the introduction of biomass use in electricity generation does shift the aggregate electricity supply curve downward). More specifically, our results show that the biomass-technology employed has to be sufficiently clean on a life-cycle basis relative to the fossil ones so that biomass-energy introduction leads to a mitigation of $\mathrm{CO}_{2}$ emissions. Otherwise, even though biomass-based electricity is cleaner than fossil-based electricity (in terms of $\mathrm{CO}_{2}$ emissions per $\mathrm{kWh}$ of electricity produced), total $\mathrm{CO}_{2}$ emissions might even rise as aggregate electricity consumption increases due to the rebound effect.

Regarding policy, the utilization of biomass for producing renewable electricity (or heat) - a major part of the bioeconomy - has important implications for the sustainable development of the agricultural and natural resource sectors. However, the development of this industry requires significant investment in research and infrastructure as well as policies for efficient and equitable transfer of technologies from the public to the private sector. It is likely that we will observe in the (near) future the emergence of multiple recommendations for policy and institutional designs conducive to the development and deployment of biomass-energy technologies. We are also likely to observe demand for tools to assess biomass-energy policies' economic and environmental impacts-the creation of such tools should be a major priority. To this end, it is important to understand the bioenergy industry as a whole and identify potential supply chain structures that could secure the level of production of biomass-based electricity required to achieve the various policy goals.

Careful consideration needs also to be given to the benefits of biomass-based electricity generation vis-à-vis the benefits of possible alternative uses of the biomass resource. For example, biomass can be used to produce renewable electricity (as in this paper), and the technologies therein can become carbon negative. Alternatively, biomass can be used in producing biofuels for the transportation sector. At the same time, bioelectricity can be utilized as a transportation fuel itself, especially in areas with relatively short driving distances. Another possible use of biomass is in producing hydrogen and/or ammonia, and even though the relevant technologies are very far from commercialization, their long-run potential is enormous.

Last, many countries, particularly among the developed member countries of the Organization for Economic Co-operation and Development, are pursuing policies and implementing regulations so as to increase the pressure on electricity generators to reduce their GHG emissions by decreasing fossil fuel use. As a result, the renewable share of total world electricity generation is rising. According to recent projections by the U.S. Energy Information Administration [5], total electricity generation from renewable resources will increase on average by $2.9 \%$ /year over the period 2012-2040, with electricity generation from non-hydropower renewables being the predominant source of this increase, projected to grow annually by $5.7 \%$-in comparison, the corresponding figure for coal-based generation is $0.8 \% / y e a r$. Further, of the 5.9 trillion kWh of new renewable electricity that will be added to world supply over the period 2012-2040, biomass- and waste-based electricity generation will contribute close to 856 billion $\mathrm{kWh}$ (i.e., $14 \%$ of the total)—a small part of the 856 billion $\mathrm{kWh}$ will come from tidal/wave/ocean energy.

Focusing on South Korea, the introduction of the RPS system in 2012 has boosted interest in using biomass and wood pellets for energy generation. Wood pellets in particular are primarily used with coal in South Korea in co-firing applications, and their growing demand is met by imports coming mainly from Canada, Southeast Asia, and the United States. According to Bloomberg New Energy Finance, South Korea's demand for wood pellets in 2014 was estimated at 2.2 million short tons, being roughly equal to $40 \%$ of the respective demand in the United Kingdom [5].

In general, co-firing coal with biomass, especially when coupled with carbon capture and storage technologies, can produce substantial economic and environmental benefits [38,40]. A promising alternative for South Korea to co-firing is bioenergy generation along with carbon capture and storage (i.e., BECCS). BECCS refers to the production of energy using biomass coupled with the capturing and subsequent storing of the resulting $\mathrm{CO}_{2}$ emissions (e.g., underground geological storage or ocean 
storage), leading to negative overall emissions. Of course, besides its obvious environmental benefits, BECCS can greatly contribute to rural development as forestry and agricultural residues can be utilized as biomass feedstocks for energy production. We believe this is an important research avenue to pursue, but we also leave it for the future.

\section{Concluding Remarks}

We have demonstrated that the introduction of biomass-based electricity production can yield substantial benefits to South Korea, especially on the environmental front. We first approximated the theoretical (i.e., upper-bound) biomass potential from forestry residues, livestock manure, and staple crops and used the existing literature to calculate the amount of electricity that could be theoretically generated using these different biomass feedstocks. Our preliminary analysis suggests that the bioelectricity potential of South Korea is very significant. Out of all the feedstocks and technologies considered, pyrolysis of forestry residues could potentially impact the electricity market the most. We then calibrated a linear demand and supply system for the Korean electricity market and, subsequently, performed Monte Carlo simulations in order to address any uncertainty with respect to our model's elasticity parameters. More precisely, we simulated different bioelectricity supply shocks while randomly perturbing the demand and supply elasticities (separately). Our findings show that the introduction of bioelectricity results in an increase in total electricity consumption and in a decrease in the market price of electricity. As a result, an environmentally detrimental rebound effect arises whereby fossil-based electricity production declines by less than the size of the bioelectricity supply shock considered. For example, when perturbing the demand elasticity and under an ambitious scenario of a $25 \%$ bioelectricity supply shock, fossil-based electricity generation decreases, on average, by only $10.6 \%$, implying a $57.6 \%$ rebound effect. However, $\mathrm{CO}_{2}$ emissions are still reduced by 94 million tonnes in the most favorable (environmentally) biomass-technology scenario examined. And aggregate welfare in the economy does rise.

Author Contributions: G.H.: Conceptualization; methodology; software; validation; formal analysis; investigation; resources; data curation; writing-original draft preparation; writing-review and editing; visualization; supervision; project administration; funding acquisition. C.T.: Conceptualization; methodology; software; validation; formal analysis; investigation; resources; data curation; writing-original draft preparation; writing — review and editing; visualization; supervision; project administration; funding acquisition. All authors have read and agreed to the published version of the manuscript.

Funding: This research was funded by the Korea Development Institute under an Adjunct Fellow appointment of Chrysostomos Tabakis during the period 09/15/2016-09/14/2017.

Acknowledgments: This paper is written based on Hochman, Gal, and Tabakis, Chrysostomos, "Biomass to Electricity: The Case of South Korea," KDI Working Paper 2017-02, 2017. The authors thank the editor and three anonymous referees for constructive and insightful comments that significantly improved the paper. The authors infinitely thank Saketh Aleti, DongWhoi Moon, and Heejung Yun for excellent research assistantship. Any remaining errors are the authors' doing.

Conflicts of Interest: The authors declare no conflict of interest.

\section{References}

1. BP. BP Statistical Review of World Energy 2020. 2020. Available online: https://www.bp.com/en/global/ corporate/news-and-insights/press-releases/bp-statistical-review-of-world-energy-2020-published.html (accessed on 15 July 2020).

2. U.S. Energy Information Administration. Country Analysis Brief: South Korea. 2018. Available online: http://www.ieee.es/en/Galerias/fichero/OtrasPublicaciones/Internacional/2018/EIA_south_korea_ 20jul2018.pdf (accessed on 15 July 2020).

3. Kim, H.; Shin, E.-S.; Chung, W.-J. Energy demand and supply, energy policies, and energy security in the Republic of Korea. Energy Policy 2011, 39, 6882-6897. [CrossRef]

4. Ros, A.J. An econometric assessment of electricity demand in the United States using utility-specific panel data and the impact of retail competition on prices. Energy J. 2017, 38, 73-99. [CrossRef] 
5. U.S. Energy Information Administration. International Energy Outlook 2016. 2016. Available online: https://www.eia.gov/outlooks/ieo/pdf/0484(2016).pdf (accessed on 30 April 2017).

6. Jebaraj, S.; Iniyan, S. A review of energy models. Renew. Sustain. Energy Rev. 2006, 10, 281-311. [CrossRef]

7. Swan, L.G.; Ugursal, V.I. Modeling of end-use energy consumption in the residential sector: A review of modeling techniques. Renew. Sustain. Energy Rev. 2009, 13, 1819-1835. [CrossRef]

8. Urpelainen, J.; Yang, J. Global patterns of power sector reform, 1982-2013. Energy Strategy Rev. 2019, 23, 152-162. [CrossRef]

9. Ortner, A.; Totschnig, G. The future relevance of electricity balancing markets in Europe-A 2030 case study. Energy Strategy Rev. 2019, 24, 111-120. [CrossRef]

10. Kim, Y.J.; Wilson, C. Analysing future change in the EU's energy innovation system. Energy Strategy Rev. 2019, 24, 279-299. [CrossRef]

11. Krichene, N. World crude oil and natural gas: A demand and supply model. Energy Econ. 2002, 24, 557-576. [CrossRef]

12. Canyurt, O.E.; Ceylan, H.; Ozturk, H.K.; Hepbasli, A. Energy demand estimation based on two-different genetic algorithm approaches. Energy Sources 2004, 26, 1313-1320. [CrossRef]

13. Hwang, I.C. Seoul energy demand forecast 2015-2035: An application of the MAED. J. Environ. Policy Adm. 2015, 23, 47-76. (In Korean) [CrossRef]

14. Bae, Y. Estimation and forecast of long-run energy demand function: A cointegration approach. Korean Energy Econ. Rev. 2015, 14, 21-50. (In Korean)

15. Lee, H.R.; Shin, H. Electricity demand forecasting based on support vector regression. IE Interfaces 2011, 24, 351-361. (In Korean) [CrossRef]

16. Shin, D.; Jo, H.-H.; Kim, J. An analysis of Korean energy consumption volatility. Stud. Econ. 2015, 63, 71-119. (In Korean)

17. Lee, S.-J.; Euh, S.-S.; Yoo, S.-H. Estimation of city gas demand function using time series data. J. Energy Eng. 2013, 22, 370-375. (In Korean) [CrossRef]

18. Kim, J.-S.; Yang, C.-S.; Park, J.-G. An empirical study on the consumption function of Korean natural gas for city gas-Using time varying coefficient time series model. J. Energy Eng. 2011, 20, 318-329. (In Korean) [CrossRef]

19. Chung, W.-S.; Tohno, S.; Shim, S.Y. An estimation of energy and GHG emission intensity caused by energy consumption in Korea: An energy IO approach. Appl. Energy 2009, 86, 1902-1914. [CrossRef]

20. Tareen, W.U.K.; Dilbar, M.T.; Farhan, M.; Nawaz, M.A.; Durrani, A.W.; Memon, K.A.; Mekhilef, S.; Seyedmahmoudian, M.; Horan, B.; Amir, M.; et al. Present status and potential of biomass energy in Pakistan based on existing and future renewable resources. Sustainability 2020, 12, 249. [CrossRef]

21. Nunes, L.J.R.; Matias, J.C.O.; Catalão, J.P.S. Biomass in the generation of electricity in Portugal: A review. Renew. Sustain. Energy Rev. 2017, 71,373-378. [CrossRef]

22. Ericsson, K.; Werner, S. The introduction and expansion of biomass use in Swedish district heating systems. Biomass Bioenergy 2016, 94, 57-65. [CrossRef]

23. Muratori, M.; Calvin, K.; Wise, M.; Kyle, P.; Edmonds, J. Global economic consequences of deploying bioenergy with carbon capture and storage (BECCS). Environ. Res. Lett. 2016, 11, 095004. [CrossRef]

24. Korean Statistical Information Service (KOSIS). Available online: http://kosis.kr/statisticsList/statisticsList_ 01List.jsp?vwcd=MT_ZTITLE\&parentId=F (accessed on 27 April 2017).

25. Food and Agriculture Organization of the United Nations (FAO). Available online: http://www.fao.org/ faostat/en/\#data/QC (accessed on 1 April 2017).

26. Kofman, P.D. Units, Conversion Factors and Formulae for Wood for Energy. COFORD, Harvesting/Transportation. 2010. Available online: http://woodenergy.ie/media/coford/content/publications/ projectreports/cofordconnects/ht21.pdf (accessed on 20 April 2017).

27. Shelly, J.R. Woody Biomass Definitions and Conversion Factors. UC Berkeley, 2007. Available online: http://ucanr.edu/sites/WoodyBiomass/newsletters/IG003_-_Woody_Biomass_Definitions_and_ Conversions_Factors31510.pdf (accessed on 20 April 2017).

28. Christie, C.; Guadagno, K.; Solomon, L. 2011 New Jersey Energy Master Plan. State of New Jersey. Available online: http://nj.gov/emp/docs/pdf/2011_Final_Energy_Master_Plan.pdf (accessed on 20 April 2017). 
29. Cho, S.-H.; Kim, T.; Kim, H.J.; Park, K.; Roberts, R.K. Regionally-varying and regionally-uniform electricity pricing policies compared across four usage categories. In Proceedings of the 2015 Agricultural \& Applied Economics Association and Western Agricultural Economics Association Joint Annual Meeting, San Francisco, CA, USA, 26-28 July 2015.

30. Korea Energy Economics Institute. Analysis on Impact of Electricity Price Change on Demand. KEPCO, 2012. Available online: https://www.keei.re.kr/main.nsf/index_en.html (accessed on 15 April 2017). (In Korean).

31. Central Intelligence Agency. The World Factbook. Available online: https://www.cia.gov/library/publications/ resources/the-world-factbook/fields/253rank.html (accessed on 28 August 2020).

32. Brennan-Tonetta, M.; Hochman, G.; Schilling, B. Impact of political economy and logistical constraints on assessments of biomass energy potential: New Jersey as a case study. In Modeling, Dynamics, Optimization and Bioeconomics I; Springer Proceedings in Mathematics \& Statistics; Pinto, A.A., Zilberman, D., Eds.; Springer: Cham, Switzerland, 2014; Volume 73, pp. 111-124.

33. International Energy Agency (IEA). Renewable Portfolio Standard (RPS). Available online: https://www.iea. org/policies/4837-renewable-portfolio-standard-rps?country=Korea (accessed on 28 August 2020).

34. Azevedo, I.; Jaramillo, P.; Rubin, E.; Yeh, S. Modeling Technology Learning for Electricity Supply Technologies. 2013. Available online: https://www.cmu.edu/epp/iecm/rubin/PDF\%20files/2013/FINAL\%20PHASE\%20I\% 20REPORT\%20TO\%20EPRI_May25.pdf (accessed on 15 April 2017).

35. Rubin, E.S.; Azevedo, I.M.L.; Jaramillo, P.; Yeh, S. A review of learning rates for electricity supply technologies. Energy Policy 2015, 86, 198-218. [CrossRef]

36. U.S. Energy Information Administration. Capital Cost Estimates for Utility Scale Electricity Generating Plants. 2016. Available online: https://www.eia.gov/analysis/studies/powerplants/capitalcost/pdf/capcost_ assumption.pdf (accessed on 15 May 2017).

37. Trancik, J.E.; Brown, P.R.; Jean, J.; Kavlak, G.; Klemun, M.M.; Edwards, M.R.; McNerney, J.; Miotti, M.; Mueller, J.; Needell, Z. Technology Improvement and Emissions Reductions as Mutually Reinforcing Efforts: Observations from the Global Development of Solar and Wind Energy; MIT: Cambridge, MA, USA, 2015; Available online: https://dspace.mit.edu/handle/1721.1/102237 (accessed on 15 May 2017).

38. Spath, P.L.; Mann, M.K. Biomass Power and Conventional Fossil Systems with and without CO2 Sequestration-Comparing the Energy Balance, Greenhouse Gas Emissions and Economics; Technical Report NO. NREL/TP-510-32575; National Renewable Energy Lab.: Golden, CO, USA, 2004. Available online: https:/www.osti.gov/biblio/15006537-biomass-power-conventional-fossil-systems-without-co2sequestration-comparing-energy-balance-greenhouse-gas-emissions-economics (accessed on 20 May 2017).

39. U.S. Energy Information Administration. Carbon Dioxide Emissions Coefficients. Available online: https://www.eia.gov/environment/emissions/co2_vol_mass.php (accessed on 14 February 2017).

40. Gopalakrishnan, H.; Liao, T.; Norton, C.; Hochman, G. Coal, co-firing, and bioenergy carbon capture and storage: The case of the Mid-Atlantic and Northeast regions. In Proceedings of the 2017 Aresty Undergraduate Research Symposium, New Brunswick, NJ, USA, 28 April 2017.

(C) 2020 by the authors. Licensee MDPI, Basel, Switzerland. This article is an open access article distributed under the terms and conditions of the Creative Commons Attribution (CC BY) license (http://creativecommons.org/licenses/by/4.0/). 